\title{
Folate bioavailability
}

\author{
Helene McNulty* and Kristina Pentieva \\ Northern Ireland Centre for Food and Health (NICHE), School of Biomedical Sciences, \\ University of Ulster, Coleraine BT52 1SA, UK
}

\begin{abstract}
The achievement of optimal folate status to prevent neural-tube defects, and possibly other diseases, is hindered by the well-recognised incomplete bioavailability of the natural folates found in foods compared with the synthetic vitamin, folic acid. Folate bioavailability from different foods is considered to be dependent on a number of factors, including the food matrix, the intestinal deconjugation of polyglutamyl folates, the instability of certain labile folates during digestion and the presence of certain dietary constituents that may enhance folate stability during digestion. There is conflicting evidence as to whether the extent of conjugation of polyglutamyl folate (in the absence of specific inhibitors of deconjugation in certain foods) is a limiting factor in folate bioavailability. Estimates of the extent of lower bioavailability of food folates compared with folic acid (relative bioavailability) show great variation, ranging anywhere between 10 and $98 \%$, depending on the methodological approach used. The lack of accurate data on folate bioavailability from natural food sources is of particular concern in those countries in which there is no mandatory folic acid fortification, and therefore a greater reliance on natural food folates as a means to optimise status. Apart from the incomplete bioavailability of food folates, the poor stability of folates in foods (particularly green vegetables) under typical conditions of cooking can substantially reduce the amount of vitamin ingested and thereby be an additional factor limiting the ability of food folates to enhance folate status. A recent workshop convened by the Food Standards Agency concluded that gaining a better understanding of folate bioavailability in representative human diets is a high priority for future research.
\end{abstract}

Food folate: Folic acid: Folate bioavailability methodology: Folate requirements

Folate bioavailability refers to the proportion of ingested folate that is absorbed and becomes available for metabolic processes or storage. This B-vitamin has been attracting major scientific and public health interest in recent years. Apart from its well-established role in the prevention of neural-tube defects (Medical Research Council Vitamin Study Research Group, 1991; Czeizel \& Dudas, 1992), newer potential roles for folate in protecting against CVD (Wald et al. 2002; Strain et al. 2004), certain cancers (Choi \& Mason, 2000) and neuro-psychiatric conditions (Seshadri et al. 2002) are emerging. However, when dietary intakes are viewed from the perspective of optimising folate status to levels associated with lowest risk of disease, rather than merely preventing overt folate deficiency (i.e. megaloblastic anaemia), it is clear that typical folate intakes are suboptimal in the diets of many individuals. This widespread under-provision of folate is generally attributed to the poor bioavailability of natural food folates. Although there is general agreement among experts that the bioavailability of natural food folates is incomplete when compared with the synthetic vitamin, folic acid (FA), the extent to which bioavailability is reduced is somewhat controversial. Estimates of the extent of lower bioavailability of food folates compared with FA (relative bioavailability) show great variation in human studies, ranging anywhere between 10 and 98\% (Tamura \& Stokstad, 1973; Coleman et al. 1975; Baker et al. 1978; Sauberlich et al. 1987; Brouwer et al. 1999; PrinzLangenohl et al. 1999).

As a result of the major current focus and debate on FA fortification of foods, the issue of incomplete bioavailability of natural folates may be considered unimportant.

\footnotetext{
Abbreviations: DFE, dietary folate equivalents; FA, folic acid; GCPII, glutamate carboxypeptidase II.

*Corresponding author: Professor Helene McNulty, fax +44 287032 4965, email h.mcnulty@ulster.ac.uk
} 
However, it remains a fundamental concern for two reasons. First, there are many countries that do not have legislation in place for the mandatory fortification of grain food with FA similar to that introduced in recent years in North America (Fletcher et al. 2004). Such countries are therefore reliant mainly on natural food folates as a means to optimise status. Second, irrespective of whether a country has a FA fortification policy, the issue of setting dietary folate recommendations remains an ongoing concern for policy makers. The focus here has generally shifted in recent years from the traditional approach of preventing overt deficiency to the newer evidence-based approach of setting dietary requirements on the basis of optimal health. However, in the case of folate, recommendations based on an adjustment for the differences in bioavailability between natural food folates and the synthetic vitamin are emerging, with the recent introduction of 'dietary folate equivalents' (DFE; Institute of Medicine, 1998) in the USA. The DFE is defined as the quantity of natural food folate plus 1.7 times the quantity of FA in the diet; this definition is based on the assumption that the bioavailability of FA added to food is greater than that of natural food folate by a factor of 1.7 . This estimation is, however, highly dependent on one metabolic study in non-pregnant women that estimated the bioavailability of food folates to be $\leq 50 \%$ relative to that of FA (Sauberlich et al. 1987), and other evidence showing that FA added to food has about $85 \%$ of the bioavailability of free FA (Pfeiffer et al. 1997). Other countries wishing to consider the use of this approach or a similar one for setting dietary folate recommendations require accurate and meaningful folate bioavailability data in order to confirm the robustness of the US DFE value.

The present review will address the various factors that are considered to contribute to the incomplete bioavailability of natural folates from foods, the experimental approaches that have been used to examine food folate bioavailability, the major findings from recent bioavailability studies in human subjects and future research priorities.

\section{Factors considered to contribute to the incomplete bioavailability of natural food folates}

The bioavailability of folates from various foods is considered to be dependent on a number of factors, including: intestinal deconjugation of polyglutamyl folates; the food matrix; the instability of certain labile folates during digestion (or before ingestion); the presence of certain dietary constituents that may enhance folate stability during digestion (e.g. folate-binding proteins, ascorbate).

\section{Factors related to intestinal deconjugation of food folates}

In contrast to synthetic FA, which is a monoglutamate, natural food folates are predominantly polyglutamates with a variable number of glutamate residues. A recent study from The Netherlands has estimated that approximately two-thirds of total folate intake from a mixed unfortified diet is in the polyglutamyl form, derived mainly from vegetables (Melse-Boonstra et al. 2002). These polyglutamates need to be hydrolysed to the monoglutamate form for normal absorption in the proximal small intestine. This process is controlled by the intestinal brush-border enzyme glutamate carboxypeptidase II (GCPII).

GCPII has a pH optimum at 6-7 (Halsted, 1990) and ingestion of foods that can change the intestinal $\mathrm{pH}$ may result in incomplete intestinal deconjugation of polyglutamyl folates. For example, Tamura et al. (1976) have found a marked reduction in the bioavailability of heptaglutamate when added to $600 \mathrm{ml}$ diluted orange juice in comparison with FA. The authors have established that the reduction in heptaglutamate bioavailability is as a result of the lowering of $\mathrm{pH}$ (to 3.7) by the high load of orange juice. They have shown that heptaglutamate bioavailability is reduced when citric acid is added to orange juice, but when the same mixture is neutralised to $\mathrm{pH} \mathrm{6.4} \mathrm{the} \mathrm{bioavailability} \mathrm{of}$ heptaglutamate does not differ from that of FA (Tamura et al. 1976). In addition, some food components and certain drugs have been reported to act as inhibitors of the activity of GCPII. Studies with stable isotopes in human subjects (Wei et al. 1996) and in vitro experiments with porcine jejunal brush-border membrane (Wei \& Gregory, 1998) indicate that organic acid ions (citrate, malate, ascorbate and phytate) present in orange juice have a combined inhibitory effect on the activity of GCPII. Nucleic acids in yeast ingested in large doses have also been reported to decrease the activity of GCPII (Rosenberg \& Godwin, 1971). A naturally-occurring heat-activated GCPII inhibitor has been identified in the skin of various pulses (Butterworth et al. 1974); however, later bioavailability studies with human subjects have failed to detect any effect of beans on the utilisation of heptaglutamates (Keagy et al. 1988). Some drugs (salicylazosulfapyridine) and ethanol have also been reported to competitively inhibit GCPII (Halsted, 1990).

Recently, a polymorphism (C1561T) in the gene encoding GCPII has been identified and in vitro studies have found that COS-7 cells expressing the mutant variant have a $53 \%$ lower GCPII enzyme activity than cells with the wild genotype (Devlin et al. 2000). However, the frequency of the homozygous mutant genotype for this polymorphism in the general population is very low $(0.5 \%)$, and its in vivo effects on dietary folate digestion and folate status remain unclear, since various human studies have shown contradictory results (Devlin et al. 2000; Lievers et al. 2002; Vargas-Martinez et al. 2002; Afman et al. 2003).

The question as to whether polyglutamyl folates are inherently less bioavailable than monoglutamyl folates (i.e. in the absence of specific inhibitors of deconjugation such as organic acids) remains to be resolved. The bioavailability of folate polyglutamates relative to monoglutamates has been explored in different studies with various results. Earlier acute studies (Godwin \& Rosenberg, 1975; Keagy et al. 1988), together with a recent chronic study by MelseBoonstra et al. (2004), have indicated that the bioavailability of polyglutamyl folate is markedly lower than that of monoglutamyl folate. In contrast, recent results (Hannon-Fletcher et al. 2004) have found no evidence to support the view that the extent of glutamation per se is a 
limiting factor in the bioavailability of folates from natural food sources. A 6-week intervention study with healthy subjects has shown no difference in the bioavailability of folates from yeast (providing $100 \%$ of the folate as polyglutamyl folate) and spinach (Spinacia oleracea; providing $50 \%$ of the folate as polyglutamyl folate). These observations are in good agreement with previous findings (Wei et al. 1996) from studies using exogenous ${ }^{2} \mathrm{H}$ labelled monoglutamyl and polyglutamyl folates added to various foods that have shown equivalent bioavailability for the two forms of folate. Similar findings have also been reported by Konings et al. (2002) in an acute study of subjects with an ileostomy that compared folate absorption from spinach containing $60 \%$ of the folate as polyglutamate and spinach pretreated before ingestion to convert the folates to the monoglutamate form. All such findings showing a similar bioavailability for polyglutamyl and monoglutamyl folate forms are consistent with earlier observations (Halsted, 1990) indicting that the activity of the human jejunal brush-border enzyme GCPII exceeds that needed for hydrolysis of polyglutamyl folates within the range of dietary intake and is, therefore, not rate limiting in the absorption process.

\section{Factors related to the food matrix}

Since folates are covalently bound to macromolecules in foods, the food matrix as a whole and its components can also influence folate bioavailability by entrapment in the matrix, thereby hindering diffusion to the absorptive surface during digestion. Incomplete release from plant cellular structure may be a factor affecting folate bioavailability in certain plants. Two independent studies have demonstrated that folate bioavailability from minced, chopped or enzymically-liquefied spinach is higher than that from whole spinach leaves when equal amounts of spinach folates are provided to human volunteers (van het Hof et al. 1999; Castenmiller et al. 2000). The effects of wheat bran and dietary fibre on folate bioavailability have been explored in various acute and longer-term studies in human subjects, but the results are inconsistent (Bailey et al. 1988; Keagy et al. 1988; Castenmiller et al. 2000). In vitro studies with intestinal brush-border-membrane vesicles have indicated that dietary fibre does not affect the activity of GCPII (Bhandari \& Gregory, 1990).

\section{Factors related to chemical instability of food folates}

Unlike FA, which is a fully-oxidised molecule, natural folates are a mixture of reduced forms with or without $\mathrm{C}_{1}$ substitution of the pteridine ring. The chemical structure of FA renders it very stable to oxidation and resistant to destruction (Colman et al. 1975), whereas natural folates are labile and prone to oxidative cleavage at the C-9-N-10 bond (Murphy et al. 1976). There are two consequences in relation to folate availability. First, extensive losses of folate can occur during cooking and preparation of foods, which may considerably reduce the amount of folate ingested. Folate losses in the range of $50-80 \%$ have been reported in green vegetables after boiling (Hurdle et al. 1968; Leichter et al. 1978; De Souza \& Eitenmiller, 1986;
McKillop et al. 2002) and in processed legumes (Dang et al. 2000). In addition to any folate losses before ingestion, considerable instability of certain labile food folates has been demonstrated in studies in vitro that mimick the intestinal digestion of folates from various foods (Seyom \& Selhub. 1998). Thus, the instability of labile folate species in vivo may be an important factor contributing to the incomplete bioavailability of natural food folates.

As indicated by previous studies (Smith et al. 1985; Andersson \& Oste, 1992), some dietary constituents may enhance folate bioavailability by increasing the stability of food folates during food processing and during digestion in the gastrointestinal tract (e.g. folate-binding protein and antioxidants such as ascorbic acid).

\section{Other potential factors affecting food folate bioavailability}

Apart from potential factors affecting intestinal deconjugation, food matrix effects or chemical instability of food folates, the presence of other food components in the intestinal milieu may inhibit folate absorption. For example, Pfeiffer et al. (1997) have reported a small reduction in the absorption of $\left[{ }^{13} \mathrm{C}-5\right] \mathrm{FA}$ when it is administered after a light breakfast meal compared with its administration without food.

\section{Experimental approaches to determining food folate bioavailabililty}

The bioavailability of natural folates has been studied using various acute and chronic protocols that involve the administration of reduced folates either in the form of foods or commercial preparations corresponding to the major food folate forms (usually 5-methyltetrahydrofolate). Typically the bioavailability of reduced folates is compared with that of FA, since the latter, which is the form used for supplementation and food fortification purposes, is considered to be highly bioavailable.

\section{Acute studies}

The protocol used in acute folate bioavailability studies is similar to that employed in pharmacology for testing the pharmacokinetics of different drugs. Typically, in a crossover or parallel design, a single ingestion of a reference dose of reduced folates or FA is administered to human volunteers and the changes in blood and/or urinary folate concentrations are monitored at various time points. The typical variables used to compare responses between the different treatments include the maximal plasma or serum folate concentration, the time required to achieve maximal plasma or serum folate response, the calculated area under the curve for plasma or serum folate response and urinary folate measurements. On the basis of the type of folate compounds administered, acute studies may be subdivided into two categories, non-isotopic and isotopic studies.

Non-isotopic acute studies. The important methodological considerations of non-isotopic acute studies have been discussed comprehensively by other investigators (Pietrzik et al. 1990; Gregory, 1995, 2001). These 
considerations include: the administration of a folate dose sufficiently high to elicit measurable folate responses in blood or urine, but not so high that it exceeds the physiologically-relevant range; the selection of subjects with high folate status or the use of a folate presaturation protocol (otherwise the ingested dose may be preferentially directed towards depleted folate pools); frequent and substantial length (usually at least $8 \mathrm{~h}$ ) of monitoring of the folate response after ingestion of the test dose in order to ensure that the peak response is not missed and to allow sufficient time for folate concentrations to return to baseline values; the recruitment of a sufficient number of subjects for statistical power, given the variability in the folate response; the avoidance of fasting, which is reported to provoke an increase in plasma folate levels, probably by interrupting the enterohepatic folate circulation; strict control of dietary folate intake during the treatment period; the inclusion of a placebo group to control for any changes in folate measurements as a result of the conditions of the protocol.

The earliest non-isotopic acute studies using folate compounds in the physiological range of intake reported a variety of results. Perry \& Chanarin (1970) and Brown et al. (1973) demonstrated higher serum responses to reduced folates than to FA, whereas Tamura \& Stokstad (1973) were unable to show any marked differences between natural folate forms and FA, based on $24 \mathrm{~h}$ urinary folate excretion. However, the validity of these early results is questionable, given the lack of placebo treatment in any of the studies and, particularly, the short period of monitoring $(2-3 \mathrm{~h})$, which was insufficient to quantify the full plasma folate response in the studies of Perry \& Chanarin (1970 and Brown et al. (1973). A later acute study, using a very extended period of blood folate monitoring $(3 \mathrm{~d})$ and a higher folate dose $(1000 \mu \mathrm{g})$, has reported similar bioavailabilities for 5-formyltetrahydrofolate and FA, based on the area under the curve for plasma folate response (Pietrzik \& Remer, 1989). Such findings are in agreement with a recently published study (Pentieva et al. 2004) showing equivalent bioavailabilities for 5methyltetrahydrofolate and FA, based on plasma folate response measured for a $10 \mathrm{~h}$ period and using a much lower folate dose of $500 \mu \mathrm{g}$.

Few studies have explored folate bioavailability from different foods in an acute model. Tamura \& Stokstad (1973) have reported that folate bioavailability, measured by urinary folate excretion up to $24 \mathrm{~h}$ after the food consumption, varies considerably between different foods. Twelve food items were studied, of which banana and lima beans (Phaseolus limensis) were found to contain highlybioavailable folates (82-96\% relative to FA), whereas folates from other foods such as romaine lettuce, orange juice, cabbage, soybean meal and wheat germ have a low bioavailability (25-47\%). More-recent studies, based on the determination of serum folate area under the curve, have reported that the bioavailability of folates from wheataleurone flour (Fenech et al. 1999) and from spinach (Konings et al. 2002) is similar to that of an equivalent amount FA provided as a tablet. The reported differences between studies in the bioavailability of folates from various foods are probably the result of differences in the protocols used, together with any inherent differences between the foods administered, including the food matrices and other potential factors affecting folate bioavailability (GCPII inhibitors, $\mathrm{pH}$ ).

Isotopic acute studies. Isotopic studies offer the advantage of high specificity, since the only source of the labelled folate detected in the blood and/or urine can be the ingested folate isotope (Gregory, 2001). These studies became particularly attractive after the introduction of stable-isotope folate forms considered safe for human use. However, the measurement of the labelled folates and their metabolic products requires expensive and sophisticated equipment such as GC-MS or liquid chromatography-MS. In addition, most of the stable-isotope folates are not commercially available and need to be synthesised and purified by the investigators (Gregory, 1990; Maunder et al. 1999). Other investigators (Gregory \& Toth, 1990; Gregory \& Quinlivan, 2002) have reviewed the methodological requirements for stable-isotope folate studies. Two types of protocols have been used: (1) single-tracer protocols involving the monitoring of plasma folate responses after the administration of an oral dose of labelled reduced folates or FA (Wright et al. 2003); (2) dual-tracer protocols in which urinary isotope excretion ratios are compared after an oral dose of labelled reduced folates or FA and an intravenous dose of differentlylabelled FA (Gregory et al. 1992). In general, studies using both types of protocols have tended to suggest differential bioavailability of FA compared with reduced folate derivatives. However, recent isotopic studies by Wright et al. (2003) and Sanderson et al. (2003) have raised questions about the interpretation of results from acute bioavailability protocols that rely on measuring responses to the oral administration of various folates relative to a reference dose of FA. These authors have examined the rate and extent of appearance of labelled and unlabelled folates in plasma following oral doses of FA, 5-formyltetrahydrofolate or intrinsically-labelled spinach folates. The results show a marked difference in the absorption of FA $v$. the natural folates; however, all forms cause an increase in unlabelled plasma folate, and the extent of this phenomenon differs between FA and the natural folates. The authors concluded that there is a different hepatic firstpass effect between FA and the reduced folate forms, and highlighted a potential limitation with this approach arising from the displacement of unlabelled tissue folate (not originating from the oral test doses) into the plasma. Other potential limitations of this (Wright et al. 2003) and similar studies that may constrain their interpretation include the administration of the folate treatments at different doses, with subsequent mathematical adjustment of the response to an equivalent dose, and the fasting of subjects for $>16 \mathrm{~h}$, which may provoke an increase in unlabelled plasma folate by diminishing bile secretion into the gut, reported to be a major elimination route for folates (Pietrzik et al. 1990).

\section{Chronic studies}

Chronic bioavailability studies explore, usually in parallel design, the effect of long-term (typically 4-24 weeks) 
interventions with comparable doses of FA and reduced folates (specific food folates, mixed diets or commercial preparations corresponding to the major food folate forms) on markers of folate status (serum folate, erythrocyte folate, plasma homocysteine). To avoid the effect of confounding factors on the response measurement, the following categories of subjects should be excluded from participation: users of B-vitamin supplements; users of drugs affecting B-vitamin metabolism; those suffering from chronic disease. The inclusion of a placebo group is essential to control for any changes in folate measurements as a result of the conditions of the intervention. In order to accurately compare the effects of different treatments, it is important that subjects are stratified at baseline to the various treatment groups on the basis of an end point of interest, particularly if (as in the case of plasma homocysteine) the response is likely to be influenced by baseline values. In addition, subject compliance to the intervention needs to be rigorously supervised by frequent contacts and recorded on an ongoing basis during the intervention period. Furthermore, the total folate content in the treatments being administered needs to be verified at the start and during the intervention. These aspects are often overlooked in the reporting of chronic folate bioavailability studies, but are of major relevance in the interpretation of the results. If these measures are not in place to confirm that the targetted folate levels are being delivered over the intervention period, any comparison of responses to different folate treatments or different intervention doses will be very problematic.

Studies examining the effect of chronic supplementation with commercial folate preparations at doses in the range of $100-400 \mu \mathrm{g} / \mathrm{d}$ have reported similar bioavailabilities for FA and 5-methyltetrahydrofolate (Venn et al. 2002, 2003; Lamers et al. 2004). However, the results of chronic studies using food folates to estimate the bioavailability of natural folates relative to FA show great variation depending on the food source and the response index used. The interpretation of bioavailability studies involving the provision of folate-rich foods to free-living subjects may be particularly problematic as a result of a number of confounding effects. These effects include the poor stability of food folates during cooking (McKillop et al. 2002), which results in considerable and very variable folate losses before ingestion. This factor, together with poor compliance of subjects with demanding intervention protocols in long-term studies or dietary displacement of usual food folate sources with intervention foods (Cuskelly et al. 1996; Ashfield-Watt et al. 2003), may result in considerably less food folate being consumed than that targetted. In contrast, FA treatment, against which responses to food folates are typically compared, not only provides the vitamin in a very stable form, but it is likely to be associated with much greater compliance of subjects because they are required to simply ingest a tablet daily in addition to their usual diet (Cuskelly et al. 1996). Such differences can exert major confounding effects that compromise the interpretation of many folate bioavailability studies in human subjects.

One landmark study, which measured non-pregnant women for $92 \mathrm{~d}$ in a metabolic unit, estimated the bioavailability of natural folates from a mixed diet to be $\leq 50 \%$ that of FA (Sauberlich et al. 1987). Although this study was very precise, the results are based on a small number of subjects (ten subjects divided into three parallel groups) and have never been confirmed in a larger-scale metabolic study. However, in the absence of a more reliable estimate, the results of the Sauberlich et al. (1987) study have been used as the basis to set current US dietary folate recommendations, which are now expressed as DFE values (Institute of Medicine, 1998). The concept of DFE recognises for the first time the differences in bioavailability between natural food folates and the synthetic vitamin FA that is added to foods during fortification. Recent results (Hannon-Fletcher et al. 2004), based on the administration of representative food folates in a controlled (but not metabolic) 6-week intervention study, have estimated the bioavailability of food folate relative to FA to be approximately $45 \%$, consistent with the estimate of '<50\%' (Sauberlich et al. 1987) used as the cornerstone of the US DFE value. Also generally consistent with the US approach, chronic studies in free-living subjects that have compared the response of food folates with that of FA-fortified foods at equivalent intakes have shown the latter to be much more effective in increasing serum and erythrocyte folate (Cuskelly et al. 1996; Riddel et al. 2000) and reducing homocysteine (Riddel et al. 2000).

\section{Recent folate bioavailability studies and future research priorities}

The Food Standards Agency recently convened a workshop to review current research and to consider future research priorities in folate bioavailability. The full report, which includes the results of a number of recentlycompleted studies (many of which were Food Standards Agency funded), has been published elsewhere (Sanderson et al. 2003). The workshop concluded that the assessment of folate bioavailability in whole diets is a high priority for future research.

The biggest challenge in any future studies aiming to assess folate bioavailability in this way will be the delivery of food folate and FA at equivalent doses throughout the intervention period. One way in which the whole diet could be controlled would be to conduct the study in a metabolic unit. However, this approach in itself will not guarantee that the folate content of the administered foods is equivalent to the FA dose being administered in parallel. In order to ensure equivalence all meals and snacks for the intervention period (whether or not it is conducted in a metabolic unit) would need to be prepared and analysed before they are consumed. The alternative, verifying the folate content of the intervention diet after its administration (by duplicate meal analysis, for example), has proven to be problematic even in highly-controlled studies such as that of Brouwer et al. (1999), because analysis of administered foods often reveals folate levels not equivalent to the FA dose, necessitating the use of a correction factor at the analysis stage. The major reason why the amount of folates in a meal is often found on analysis to differ from that targetted is primarily a result of the welldocumented underestimation of the folate content of foods 
in current Food Tables. Using newer food folate methodology based on trienzyme (protease, amylase and conjugase) treatment (Tamura et al. 1997), much higher values have been reported recently for folates in various plant and animal foods and in composite meals (McKillop et al. 2002; Pentieva et al. 2002) compared with published folate values generated using traditional folate methodology. This finding, if confirmed, may have major implications for the calculation of dietary folate intake (and therefore folate recommendations) and requires further investigation.

\section{Conclusions}

Food folate bioavailability and the factors that affect it are poorly understood. These considerations are important, given the established and emerging roles for folate in disease prevention on the one hand, and the widespread under-provision of folate in typical diets in most European countries on the other. A number of methodological approaches have been used to address food folate bioavailability, but there are some major limitations that may confound the interpretation of studies using these various approaches. Chronic studies with food folates are likely to give the most meaningful results in future research, but only if they are based on robust and tightlycontrolled protocols to ensure the delivery of food folate and FA at equivalent doses throughout the intervention period. This challenge is a considerable one if folate bioavailability in whole diets is to be accurately assessed in order to provide quantifiable data on which to base food policy. In addition to the incomplete bioavailability of food folates generally evident from the literature, the poor stability of food folates (particularly in green vegetables) during cooking is an additional factor contributing to the limited ability of natural food folates to optimise folate status.

\section{Acknowledgements}

We wish to thank the Food Standards Agency for supporting our folate bioavailability research (project no. NO5013).

\section{References}

Afman LA, Frans JM, Trijbels \& Blom HJ (2003) The H475Y polymorphism in the glutamate carboxypeptidase II gene increases plasma folate without affecting the risk for neural tube defects in humans. Journal of Nutrition 133, 75-77.

Andersson A \& Oste R (1992) Loss of ascorbic acid, folate and vitamin B12, and changes in oxygen content of UHT-milk, II. Results and discussion. Milchwissenschaft 47, 299-302.

Ashfield-Watt PAL, Whiting JM, Clark ZE, Moat SJ, Newcombe RG, Burr ML \& McDowell IFW (2003) A comparison of the effect of advice to eat either '5-a-day' fruit and vegetables or folic acid-fortified foods on plasma folate and homocysteine. European Journal of Clinical Nutrition 57, 316-323.

Bailey LB, Barton LE, Hillier SE \& Cerda JJ (1988) Bioavailability of mono and polyglutamyl folate in human subjects. Nutrition Reports International 38, 509-518.
Baker H, Jaslow SP \& Frank O (1978) Severe impairment of dietary folate utilization in the elderly. Journal of the American Geriatrics Society 26, 218-221.

Bhandari SD \& Gregory JF (1990) Inhibition by selected food components of human and porcine intestinal pteroylpolyglutamate hydrolase activity. American Journal of Clinical Nutrition 51, 87-94.

Brouwer IA, van Dusseldorp M, West CE, Meyboom S, Thomas CMG, Duran M, van het Hof KH, Eskes TKAB, Hautvast JGAJ \& Steegers-Theunissen RPM (1999) Dietary folate from vegetables and citrus fruit decreases plasma homocysteine concentrations in humans in a dietary controlled trial. Journal of Nutrition 129, 1135-1139.

Brown JP, Scott JM, Foster FG \& Weir DG (1973) Ingestion and absorption of naturally occurring pteroylmonoglutamates (folates) in man. Gastroenterology 64, 223-232.

Butterworth CE, Newman AJ \& Krumdieck CL (1974) Tropical sprue: A consideration of possible etiologic mechanisms with emphasis on pteroylpolyglutamate metabolism. Transamerica Clinical Climatology Association 86, 11-22.

Castenmiller JJM, van de Poll CJ, West CE, Brouwer IA, Thomas CMG \& van Dusseldorp M (2000) Bioavailability of folate from processed spinach in humans. Annals of Nutrition and Metabolism 44, 163-169.

Choi SW \& Mason JB (2000) Folate and carcinogenesis: An integrated scheme. Journal of Nutrition 130, 129-132.

Colman N, Green R \& Metz J (1975) Prevention of folate deficiency by food fortification. II. Absorption of folic acid from fortified staple foods. American Journal of Clinical Nutrition 28, 459-464.

Cuskelly GJ, McNulty H \& Scott JM (1996) Effect of increasing dietary folate on red-cell folate: Implications for prevention of neural tube defects. Lancet 347, 657-659.

Czeizel AE \& Dudas I (1992) Prevention of first occurrence of neural tube defects by periconceptional vitamin supplementation. New England Journal of Medicine 327, 1832-1835.

Dang J, Arcot J \& Shrestha A (2000) Folate retention in selected processed legumes. Food Chemistry 68, 295-298.

De Souza SC \& Eitenmiller RR (1986) Effects of processing and storage on the folate content of spinach and broccoli. Journal of Food Science 51, 626-628.

Devlin AM, Ling E, Peerson JM, Fernando S, Clarke R, Smith AD \& Halsted CH (2000) Glutamate carboxypeptidase II: a polymorphism associated with lower levels of serum folate and hyperhomocysteinemia. Human Molecular Genetics 9, 2837-2844.

Fenech M, Noakes M, Clifton P \& Topping D (1999) Aleurone flour is a rich source of bioavailable folate in humans. Journal of Nutrition 129, 1114-1119.

Fletcher RJ, Bell IP \& Lambert JP (2004) Public health aspects of food fortification: a question of balance. Proceedings of the Nutrition Society 63, 605-614.

Godwin HA \& Rosenberg IH (1975) Comparative studies of the intestinal absorption of $\left[{ }^{3} \mathrm{H}\right]$ pteroylmonoglutamate and $\left[{ }^{3} \mathrm{H}\right]$ pteroylheptaglutamate in man. Gastroenterology 69, 364-373.

Gregory JF (1990) Improved synthesis of [3', 5'-2H2] folic acid: extent and specificity of deuterium labelling. Journal of Agricultural and Food Chemistry 38, 1073-1076.

Gregory JF (1995) The bioavailability of folate. In Folate: Nutritional and Clinical Perspectives, pp. 195-235. [LB Bailey, editor]. New York: Marcel Dekker.

Gregory JF (2001) Case study: folate bioavailability. Journal of Nutrition 131, 1376S-1382S.

Gregory JF, Bhandari SD, Bailey LB, Toth JP, Baumgartner TG \& Cerda JJ (1992) Relative bioavailability of deuteriumlabeled monoglutamyl tetrahydrofolates and folic acid in 
human subjects. American Journal of Clinical Nutrition 55, $1147-1153$.

Gregory JF \& Quinlivan EP (2002) In vivo kinetics of folate metabolism. Annual Review of Nutrition 22, 199-220.

Gregory JF \& Toth JP (1990) Stable-isotopic methods for in vivo investigation of folate absorption and metabolism. In Folic Acid Metabolism in Health and Disease, pp. 151-169. [MF Picciano, ELR Stokstad and JF Gregory, editors]. New York: Wiley-Liss Inc.

Halsted CH (1990) Intestinal absorption of dietary folates. In Folic Acid Metabolism in Health and Disease, pp. 23-45. [MF Picciano, ELR Stokstad and JF Gregory, editors]. New York: Wiley-Liss Inc.

Hannon-Fletcher MP, Armstrong NC, Scott JM, Pentieva K, Bradbury I, Ward M, Strain JJ, Dunn AA, Molloy AM, Scullion MA \& McNulty $\mathrm{H}$ (2004) Determination of the bioavailability of food folates in a controlled intervention study. American Journal of Clinical Nutrition (In the Press).

Hurdle ADF, Barton D \& Searles IH (1968) A method for measuring folate in foods and its application to a hospital diet. American Journal of Clinical Nutrition 21, 1202-1207.

Institute of Medicine (1998) Dietary Reference Intake; Thiamine, Riboflavin, Niacin, Vitamin B6, Folate, Vitamin B12, Pantothenic Acid, Biotin, and Choline. Washington, DC: National Academy Press.

Keagy PM, Shane B \& Oace SM (1988) Folate bioavailability in humans: effect of wheat bran and beans. American Journal of Clinical Nutrition 47, 80-88.

Konings EJM, Troost FJ, Castenmiller JJM, Roomans HHS, van den Brandt PA \& Saris WHM (2002) Intestinal absorption of different types of folate in healthy subjects with an ileostomy. British Journal of Nutrition 88, 235-242.

Lamers Y, Prinz-Langenohl R, Moser R \& Pietrzik K (2004) Supplementation with [6S]-5-methyltetrahydrofolate or folic acid equally reduces plasma total homocysteine concentrations in healthy women. American Journal of Clinical Nutrition 79, 473-478.

Leichter J, Switzer VP \& Landymore AF (1978) Effect of cooking on folate content of vegetables. Nutrition Reports International 18, 475-479.

Lievers KJA, Kluijtmans LAJ, Boers GHJ, Verhoef P, den Heijer M, Trijbels FJM \& Blom HJ (2002) Influence of glutamate carboxypeptidase II (GCPII) polymorphism $(1561 \mathrm{C} \rightarrow \mathrm{T})$ on plasma homocysteine, folate and vitamin $\mathrm{B}_{12}$ levels and its relationship to cardiovascular disease risk. Atherosclerosis $\mathbf{1 6 4}$, 269-273.

McKillop, D, Pentieva, K, Daly D, McPartlin JM, Hughes J, Strain JJ, Scott JM \& McNulty H (2002) The effect of different cooking methods on folate retention in various foods which are amongst the major contributors to folate intake in the UK diet. British Journal of Nutrition 88, 681-688.

Maunder P, Finglas PM, Mallet AI, Mellon FA, Razzaque MA, Ridge B, Vahteristo L \& Witthoft C (1999) The synthesis of folic acid, multiple labelled with stable isotopes, for bioavailability studies in human nutrition. Journal of the Chemical Society Perkin Transaction 1, 1311-1323.

Medical Research Council Vitamin Study Research Group (1991) Prevention of neural tube defects: results of the Medical Research Council Vitamin Study. Lancet 338, 131-137.

Melse-Boonstra A, de Bree A, Verhoef P, Bjorke-Monsen AL \& Verschuren WMM (2002) Dietary monoglutamate and polyglutamate folate are both associated with plasma folate concentrations in Dutch men and women aged 20-65 y. Journal of Nutrition 132, 1307-1312.

Melse-Boonstra A, West CE, Katan MB, Kok FJ \& Verhoef $P$ (2004) Bioavailability of heptaglutamyl relative to monoglutamyl folic acid in healthy adults. American Journal of Clinical Nutrition 79, 424-429.

Murphy M, Keating M, Boyle P, Weir DG \& Scott JM (1976) The elucidation of the mechanism of folate catabolism in the rat. Biochemical and Biophysical Research Communications 71, 1017-1024.

Pentieva K, Kidd JA, McKillop DJ, Strain JJ, Scott JM \& McNulty H (2002) Folate analysis of composite meals. Proceedings of the Nutrition Society 61, 92A.

Pentieva K, McNulty H, Reichert R, Ward M, Strain JJ, McKillop D, McPartlin JM, Connolly E, Molloy A, Krämer K \& Scott JM (2004) The short-term bioavailabilities of [6S]-5-methyltetrahydrofolate and folic acid are equivalent in men. Journal of Nutrition 134, 580-585.

Pfeiffer CM, Rogers LM, Bailey LB \& Gregory JF (1997) Absorption of folate from fortified cereal-grain products and of supplemental folate consumed with or without food determined by using a dual-label stable-isotope protocol. American Journal of Clinical Nutrition 66, 1388-1397.

Perry J \& Chanarin I (1970) Intestinal absorption of reduced folate compounds in man. British Journal of Haematology $\mathbf{1 8}$ 329-339.

Pietrzik K, Hages M \& Remer T (1990) Methodological aspects in vitamin bioavailability testing. Journal of Micronutrient Analysis 7, 207-222.

Pietrzik K \& Remer T (1989) Zur Bioverfugbarkeitsprufung von Mikronahrstoffen (Bioavailability study of micronutrients). Zeitschrift fur Ernahrungawissenschaft 28, 130-141.

Prinz-Langenohl R, Bronstrup A, Thorand B, Hages M \& Pietrzik K (1999) Availability of food folate in humans. Journal of Nutrition 129, 913-916.

Reisenauer AM \& Halsted CH (1987) Human folate requirements. Journal of Nutrition 117, 600-602.

Riddell LJ, Chisholm A, Williams S \& Mann JI (2000) Dietary strategies for lowering homocysteine concentrations. American Journal of Clinical Nutrition 71, 1448-1454.

Rosenberg IH \& Godwin HA (1971) Inhibition of intestinal $\gamma$ glutamyl carboxypeptidase by yeast nucleic acid: an explanation of variability in utilisation of dietary polyglutamyl folate. Journal of Clinical Investigation 50, 78a.

Sanderson P, McNulty H, Mastroiacovo P, McDowell IFW, Melse-Boonstra A, Finglas PM \& Gregory JF III (2003) Folate bioavailability: UK Food Standards Agency workshop report. British Journal of Nutrition 90, 473-479.

Sauberlich HE, Kretsch MJ, Skala JH, Johnson HL \& Taylor RC (1987) Folate requirement and metabolism in nonpregnant women. American Journal of Clinical Nutrition $\mathbf{4 6}$, 1016-1028.

Seshadri S, Beiser A, Selhub J, Jacques PF, Rosenberg IH, D'Agostino RB, Wison PWF \& Wolf PA (2002) Plasma homocysteine as a risk factor for dementia and Alzheimer's disease. New England Journal of Medicine 346, 476-483.

Seyom E \& Selhub J (1998) Properties of food folates determined by stability and susceptibility to intestinal pteroylpolyglutamate hydrolase action. Journal of Nutrition 128, 1956-1960.

Smith AM, Picciano MF \& Deering RH (1985) Folate intake and blood concentrations of term infants. American Journal of Clinical Nutrition 41, 590-598.

Strain JJ, Dowey L, Ward M, Pentieva K \& McNulty H (2004) B-vitamins, homocysteine metabolism and CVD. Proceedings of the Nutrition Society 63, 597-603.

Tamura T, Mizuno Y, Johnston KE \& Jacob RA (1997) Food folate assay with protease, $\alpha$-amylase and folate conjugase treatments. Journal of Agricultural and Food Chemistry 45 , $135-139$.

Tamura T, Shin YS, Buehring KU \& Stokstad ELR (1976) The availability of folate in man: Effect of orange juice supplement 
on intestinal conjugase. British Journal of Haematology 32, 123-133.

Tamura T \& Stokstad ELR (1973) The availability of food folate in man. British Journal of Haematology 25, 513-532.

van het Hof KH, Tijburg LBM, Pietrzik K \& Weststrate JA (1999) Influence of feeding different vegetables on plasma levels of carotenoids, folate and vitamin C. Effect of disruption of the vegetable matrix. British Journal of Nutrition 82, 203-212.

Vargas-Martinez C, Ordovas JM, Wilson PW \& Selhub J (2002) The glutamate carboxypeptidase gene II $(\mathrm{C}>\mathrm{T})$ polymorphism does not affect folate status in the Framingham Offspring cohort. Journal of Nutrition 132, 11761179

Venn BJ, Green TJ, Moser R, McKenzie JE, Skeaff CM \& Mann $\mathrm{J}$ (2002) Increases in blood folate indices are similar in women of childbearing age supplemented with [6S]-5-methyltetrahydrofolate and folic acid. Journal of Nutrition 132, 3353-3355.

Venn BJ, Green TJ, Moser R \& Mann JI (2003) Comparison of the effect of low-dose supplementation with
L-5-methyltetrahydrofolate or folic acid on plasma homocysteine: a randomized placebo-controlled study. American Journal of Clinical Nutrition 77, 658-662.

Wald DS, Law M \& Morris JK (2002) Homocysteine and cardiovascular disease: evidence on causality from a metaanalysis. British Medical Journal 325, 1-7.

Wei MM, Bailey LB, Toth JP \& Gregory JF (1996) Bioavailability for humans of deuterium-labeled monoglutamyl and polyglutamyl folates is affected by selected foods. Journal of Nutrition 126, 3100-3108.

Wei MM \& Gregory JF (1998) Organic acids in selected foods inhibit intestinal brush border pteroylpolyglutamate hydrolase in vitro: potential mechanism affecting the bioavailability of dietary polyglutamyl folate. Journal of Agricultural and Food Chemistry 46, 211-219.

Wright AJA, Finglas PM, Dainty JR, Hart DJ, Wolfe CA Southon S \& Gregory JF (2003) Single oral doses of 13C forms of pteroylmonoglutamic acid and 5-formyltetrahydrofolic acid elicit differences in short-term kinetics of labelled and unlabelled folates in plasma: potential problems in interpretation of folate bioavailability studies. British Journal of Nutrition 90, 363-371. 